\title{
Expert System Based on Fuzzy Logic: Application on Faults Detection and Diagnosis of DFIG
}

\author{
Ahmed Cheriet, Abdelkader Bekri, Abdeldjebar Hazzab, Hicham Gouabi \\ Department of Electrical Engineering, Laboratory (COASEE), Tahri Mohamed Bechar University, Algeria
}

\begin{tabular}{l} 
Article Info \\
\hline Article history: \\
Received Mar 20, 2018 \\
Revised Aug 1, 2018 \\
Accepted Aug 6, 2018 \\
\hline
\end{tabular}

\section{Keyword:}

Fault detection

Fault diagnosis

Fuzzy logic

Monitoring

Wind turbine

\begin{abstract}
Electrical energy production based on wind power is gaining area as renewable resources in the recent years because it gets clean energy with minimum cost. The major challenge for wind turbines is the electrical and the mechanical failures which can occur at any time causing damages and therefore it leads to machine downtimes and to energy production loss. To avoid this problem, several methods have been developed and used. In this paper, we proposed an expert system based on fuzzy logic which can detect and diagnosis DFIG's faults via the Stator current's signatures. The fuzzy inference system exploits the root mean square values of the stator's currents according to expert's rules to diagnosis the DFIG's state. The smart proposed expert system is verified using simulations done under Matlab/Simulink. The obtained results are very interesting and show the efficiency of the proposed strategy.
\end{abstract}

Copyright $@ 2018$ Institute of Advanced Engineering and Science. All rights reserved.

Corresponding Author:

A.Cheriet,

Department of Electrical Engineering,

Laboratory (COASEE), Tahri Mohamed Bechar University Algeria,

Bechar University, Street Of Independence, BP 417, Bechar, Algeria

Email: ahmed.cherietg@gmail.com

\section{INTRODUCTION}

With more attention paid to the energy security, ecological environment, climate change and other issues, to accelerate the development of wind power has become the consensus of the international community to promote the transformation of energy development, to cope with global climate change and concerted action. According to statistics, by the end of 2015 the global wind power installed capacity of 432 million kilowatts, spread over the world in more than and 100 countries and regions [1]. Global wind power installed capacity continues to grow; fault diagnosis technology has gradually become a hot topic in the field of wind power. For the working life of 20 years of the unit, the operation and maintenance costs generally account for the entire wind farm's total investment of $10 \%-15 \%$, while for the offshore wind farm, the overall ratio of up to $20 \%-25 \%$ [2]. Statistics show that the determining time for the fault diagnosis takes up $70 \%$ to $90 \%$ of the total time, while the repair time takes up only about $10 \%$ to $30 \%$ [3]. Therefore, efficient and accurate fault diagnosis technology is an important way to ensure the economic and safe operation of wind turbine [4]. Wind generators used in the power range of $600 \mathrm{~kW}$ to $2 \mathrm{MW}$ nowadays are mainly Doubly Fed Induction Generators (DFIG) because of their low cost of operation and maintenance when compared to the synchronous generators used for the same purpose. Modeling, control and diagnosis of DFIG is more difficult than the standard induction motor. Moreover, the DFIG is prone to electromechanical incipient faults, which gradually degrades the operating characteristics and causes major damage in the system. Of the many faults that occur in the DFIG, bearing faults, stator and rotor winding insulation failures are the most common. They lead to the short circuits as well as turn-to-turn faults in the rotor windings and stator windings respectively, which is the cause for majority of the machine failure [5]. Diagnosis is not an easy task in a complex rotating machinery because there could be many factors involved. These factors include 
type, frequency, number of alarms, effectiveness of the fault data presentation, and the time delay in fault detection. All these factors make the fault diagnosis a difficult and challenging task. Hence, there is a requirement for a real time automated condition monitoring and fault diagnosis system (CM-FDS) to aid in decision making. Shown in Figure 1.

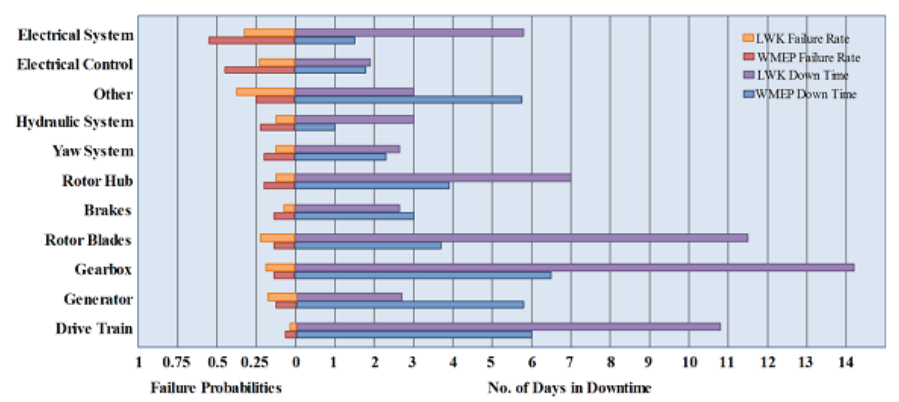

Figure 1. Failures probabilities

Where,

LWK: LandWirtschaftsKammer

WMEP: Scientific Measurement and Evaluation Program [6].

In this work the fuzzy logic theory is applied to indentify faults. The feasibility of the detection and diagnosis strategy is demonstrated with a DFIG under Matlab/Simulink.

\section{MODELING OF DFIG}

With increased penetration of wind energy into grid [7][8], wind turbine should be capable of handling faults for small period of time and remain connected to the grid during and after the fault to maintain the reliability of the system. DFIG exhibits enhanced controllability and extended speed range. Using vector control, DFIG enables decoupling of active and reactive power in addition to torque and flux. This feature helps in independent control of active and reactive power flow. Also, a cost effective power converter can be employed with a power requirement of (20-30) \% of stator power. DFIG is wound rotor induction generator whose stator output is directly connected to the grid and the rotor output is also connected to grid via back to back converters namely, Motor Side Converter (MSC) and Line Side Converter (LSC) with a DC-link capacitor in between these converters as shown in Figure 2.

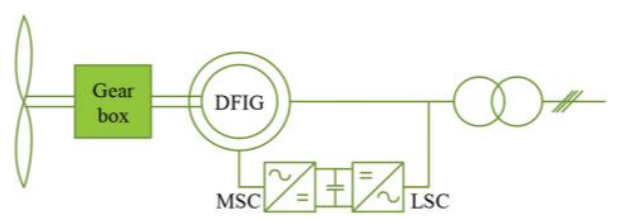

Figure 2. Layout of DFIG

Wind power available in the wind is given as follows:

$$
P_{m}=\frac{1}{2} \rho A v^{3}
$$

Where,

$\rho:$ Air density $\left(\mathrm{kg} / \mathrm{m}^{3}\right)$

A: Area swept by the blade $\left(\mathrm{m}^{2}\right)$

$\mathrm{V}$ : Velocity of the wind $(\mathrm{m} / \mathrm{s})$

Mechanical windpower is converted into mechanical torque and is given by: 


$$
T_{m}=\frac{P}{w_{w}}
$$

Where,

$w_{w}$ : Speed of wind turbine $(\mathrm{m} / \mathrm{s})$ :

The generator rortor speed can be obtained as shown in the equation:

$$
w_{r}=\int \frac{T_{e}-T_{m}}{J}
$$

Where,

$T_{e}$ : Electrical torque

$J$ : Moment of inertia $\left(\mathrm{kg} \cdot \mathrm{m}^{2}\right)$

The voltage equation of the DFIG, assuming identical stotor and rotor windings, and uniformly distributed three phase windings may be expressed as follows:

$$
\left[\begin{array}{l}
v_{S, a b c} \\
v_{R, a b c}
\end{array}\right]=-\left[\begin{array}{cc}
r_{S, a b c} & 0 \\
0 & r_{R, a b c}
\end{array}\right]\left[\begin{array}{l}
i_{S, a b c} \\
i_{R, a b c}
\end{array}\right]-\frac{d}{d t}\left[\begin{array}{l}
\psi_{S, a b c} \\
\psi_{R, a b c}
\end{array}\right]
$$

The flux linkage expressed for magnetically linear system as follows:

$$
\left[\begin{array}{l}
\psi_{S, a b c} \\
\psi_{R, a b c}
\end{array}\right]=-\left[\begin{array}{ll}
l_{S, a b c} & l_{M, a b c} \\
l_{M, a b c} & l_{R, a b c}
\end{array}\right]\left[\begin{array}{l}
i_{S, a b c} \\
i_{R, a b c}
\end{array}\right]
$$

\section{EXPERT SYSTEM BASED ON FUZZY LOGI}

The concept of fuzzy logic was introduced by Professor Lofti A. Zadeh [9] [10] to present vagueness in linguistic terms and express human knowledge in a natural way. Fuzzy logic reflects how people think. It attempts to model our sense of words, our decision making and our common sense. The fuzzy logic provides an inference mechanism for imprecise and partial information to incorporate human reasoning capabilities. Fuzzy systems use IF-THEN rules, where the IF part is called "antecedent" and the THEN part is called "consequent". The basic configuration of a pure fuzzy system is shown in Figure 3. A fuzzy inference mechanism maps fuzzy IF-THEN rules from input space to output space by using fuzzy logic methods.

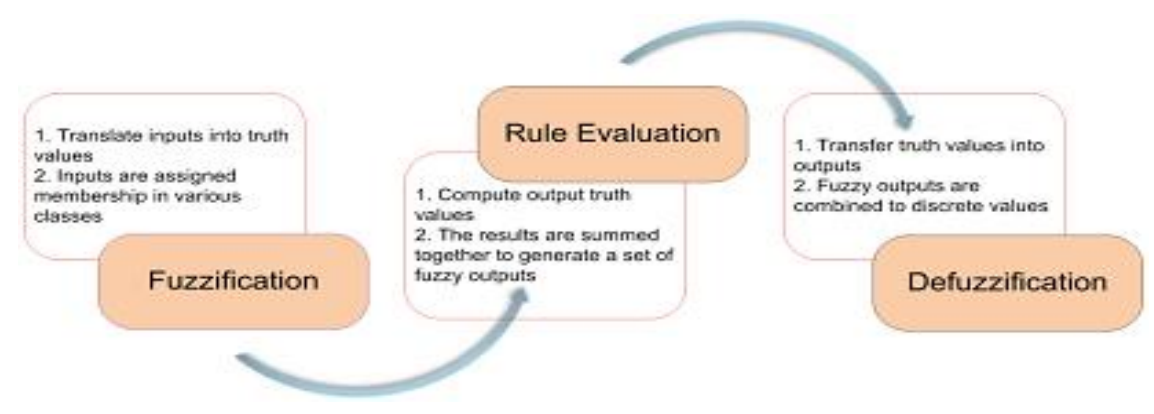

Figure 3. Fuzzy expert system

In this paper, fuzzy logic approach is used to make decisions about the DFIG conditions. The task of the diagnostic system presented here is to detect and diagnosis an upcoming stator faults as early as possible, in order to save expensive manufacturing processes or to replace faulty parts. Since stator faults do not produce clear signatures in the current spectrum, it is necessary to use other means to identify stator faults instead of the traditional spectrum analysis technique.

Expert System Based on Fuzzy Logic: Application on Faults Detection and Diagnosis of... (Ahmed Cheriet) 


\section{SIMULATION AND RESULTS ANALYSIS}

The fuzzy logic approach is applied to the DFIG current amplitudes in order to point failures in the stator. The expert system based on fuzzy logic on Figure 4 exploits all information of the three stator currents, and are used as input variable linguistics. Each input is divided on four linguistic values: Zero, Small, Normal, Medium, and big. The output linguistic variable is also divided on four linguistic values: Healthy, Sort-circuit, Dangerous short-circuit, Open circuit. The Fuzzy Inference System properties used to detect and diagnosis the current signatures of the stator is depicted on the Figure 5.

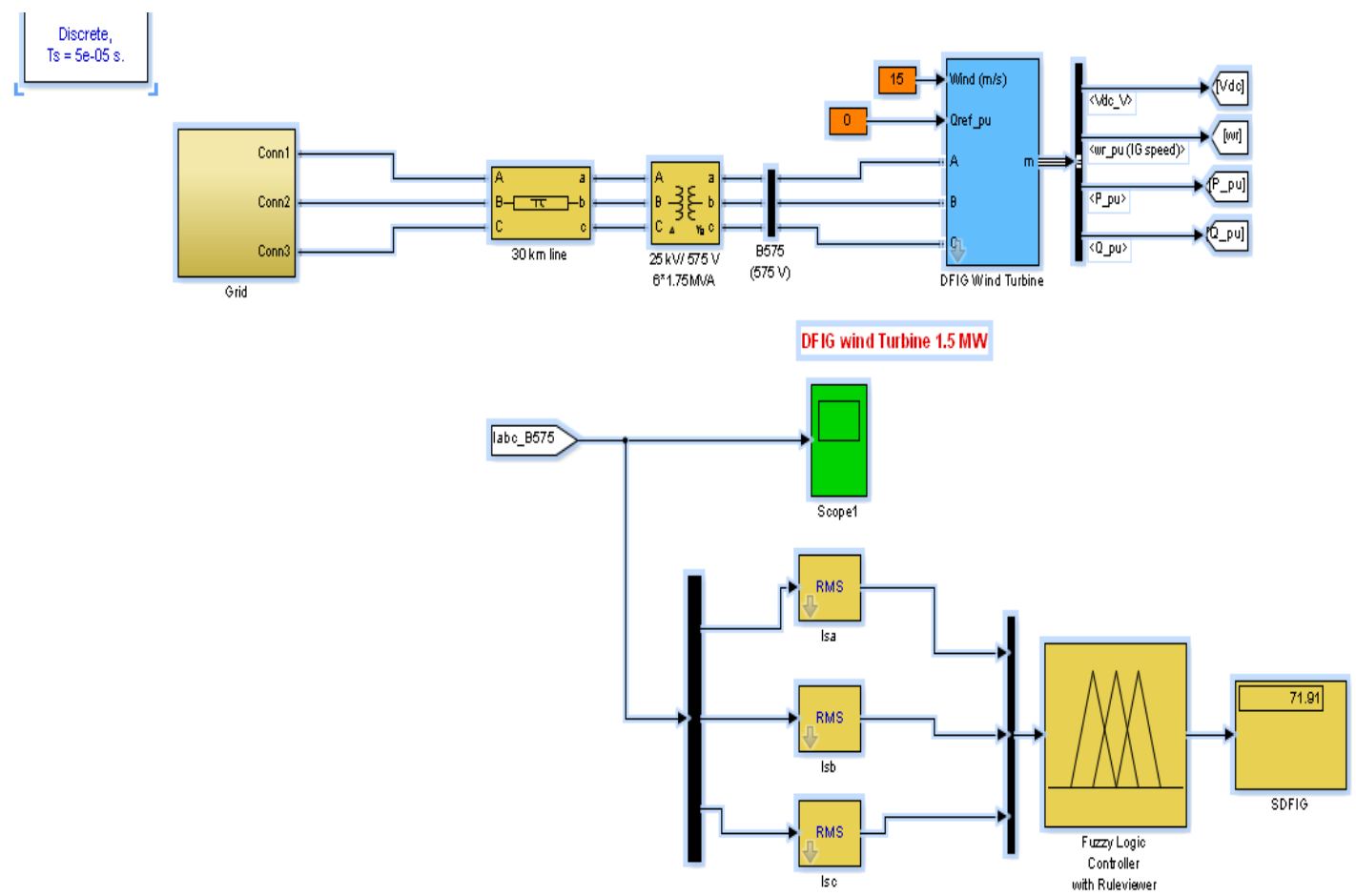

Figure 4. Layout of expert system based on fuzzy logic

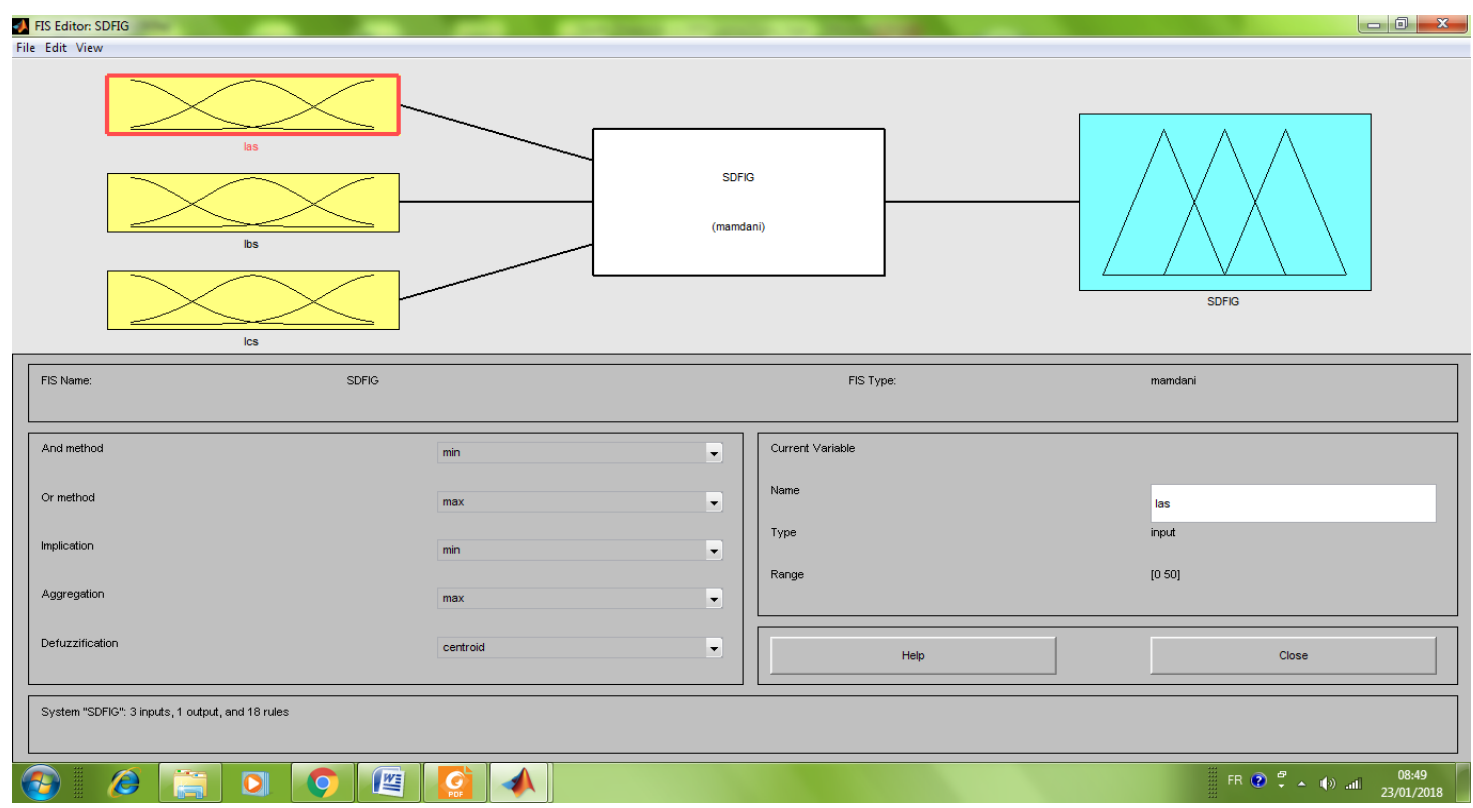

Figure 5. FIS properties 
Where,

And method $=\min$

Or method $=\max$

Implication $=\min$

Aggregation=max

Defuzzification $=$ Centroid

The centroid defuzzification returns the centre of the area under the curve according to the equation:

$$
z_{o}=\frac{\int \mu_{i}(x) x d x}{\int \mu_{i}(x) d x}
$$

The Figure 6 show respectively the membership functions of the three inputs and the output which displays the state of the DFIG. Figure 7 shows membership of the output (SDFIG).

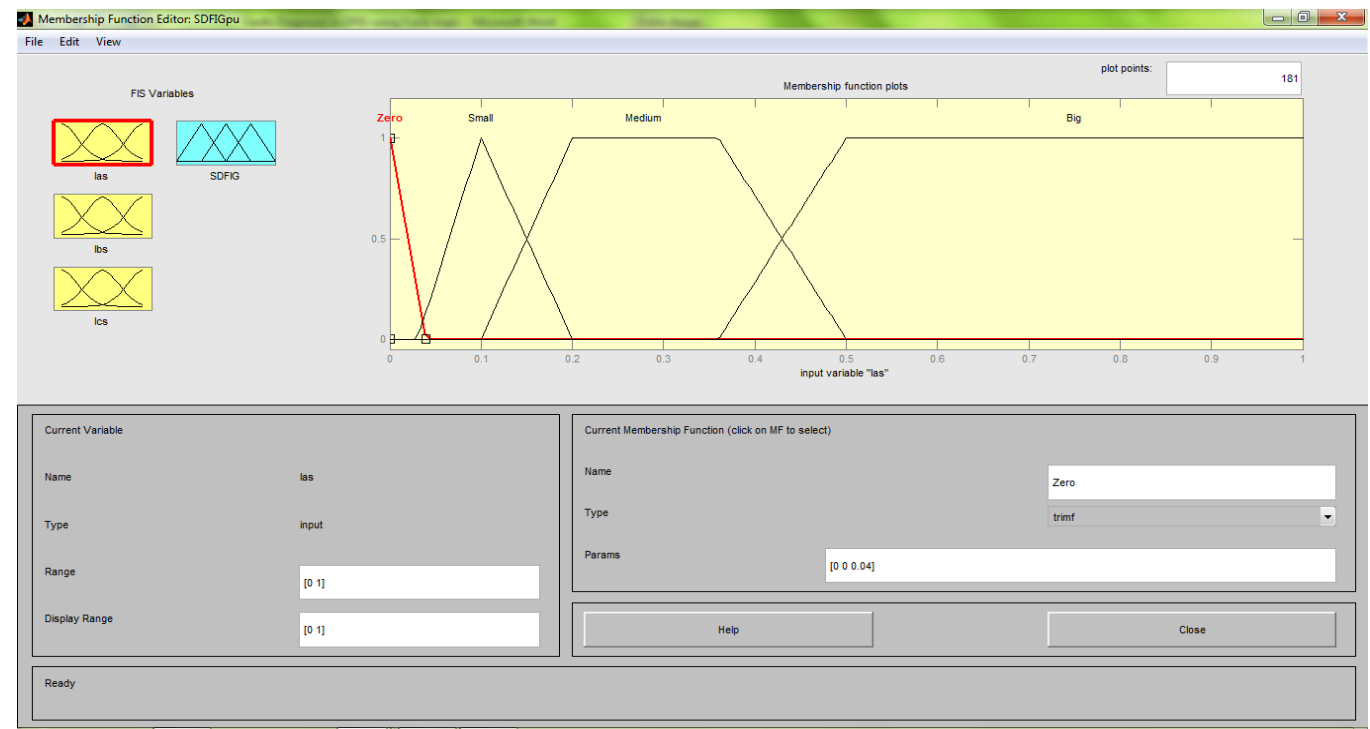

Figure 6. Membership functions of the three inputs (Ias, Iba, Ics)

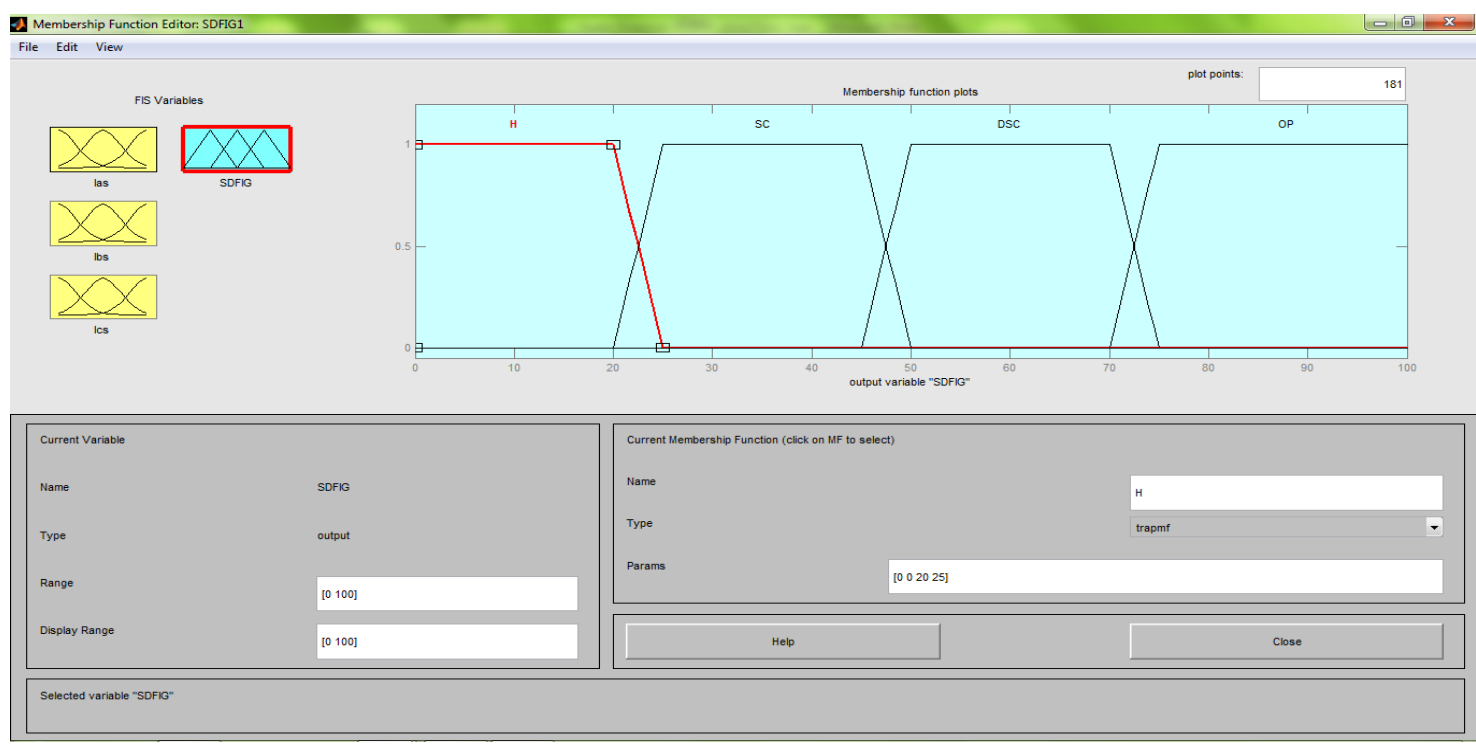

Figure 7. Membership of the output (SDFIG) 
The rules according to the experience of the expert are shown of the Figure 8 .

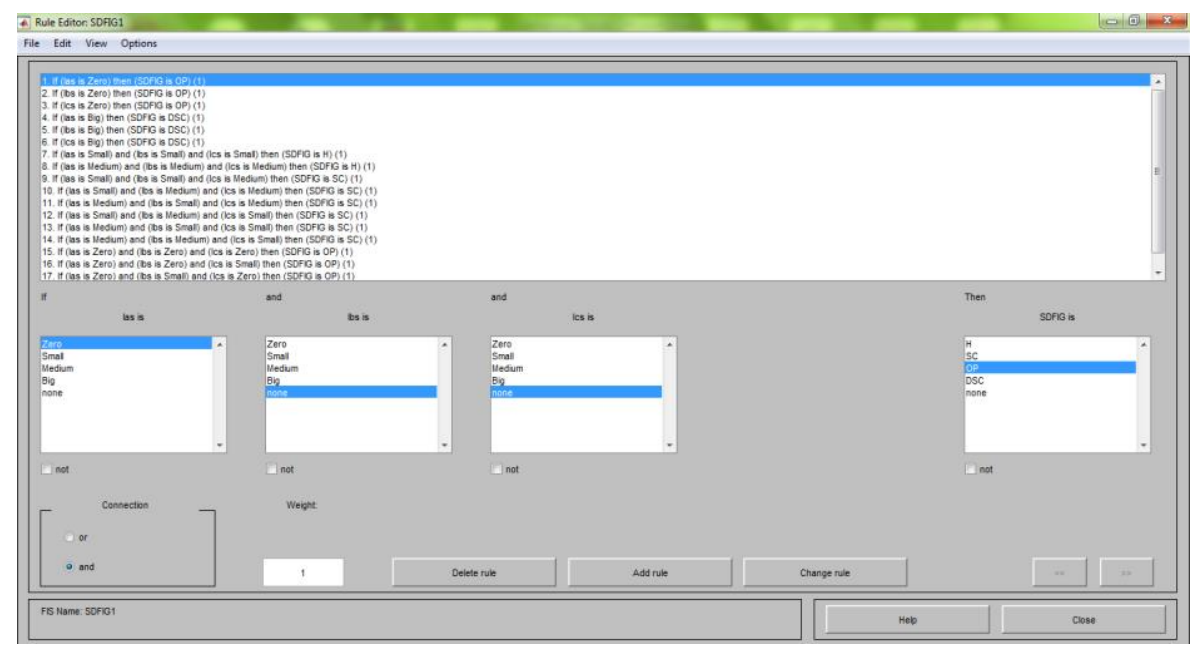

Figure 8. The expert system's rules

These rules are able to detect all faults stator's currents via their signatures. The Table 1 resumes the obtained results for DFIG's state.

Table 1 .Obtained results of faults

\begin{tabular}{cccccc}
\hline \multirow{2}{*}{ Case } & Isa(pu) & $\begin{array}{c}\text { Stator currents } \\
\text { Isb(pu) }\end{array}$ & Isc(pu) & Fuzzy Expert System value & Diagnosis \\
\hline 1 & $2.27 \mathrm{e}-08$ & 0.176 & 0.172 & 86.5 & open circuit \\
2 & 0.102 & 0.102 & 0.102 & 12 & Healthy \\
3 & 0.049 & 0.185 & 0.15 & 28 & Short circuit \\
4 & 0.034 & 0.207 & 0.190 & 71.9 & Dangerous short circuit \\
\hline
\end{tabular}

The rules viewer of DFIG's diagnostic based on fuzzy logic is shown in Figure 9-13:

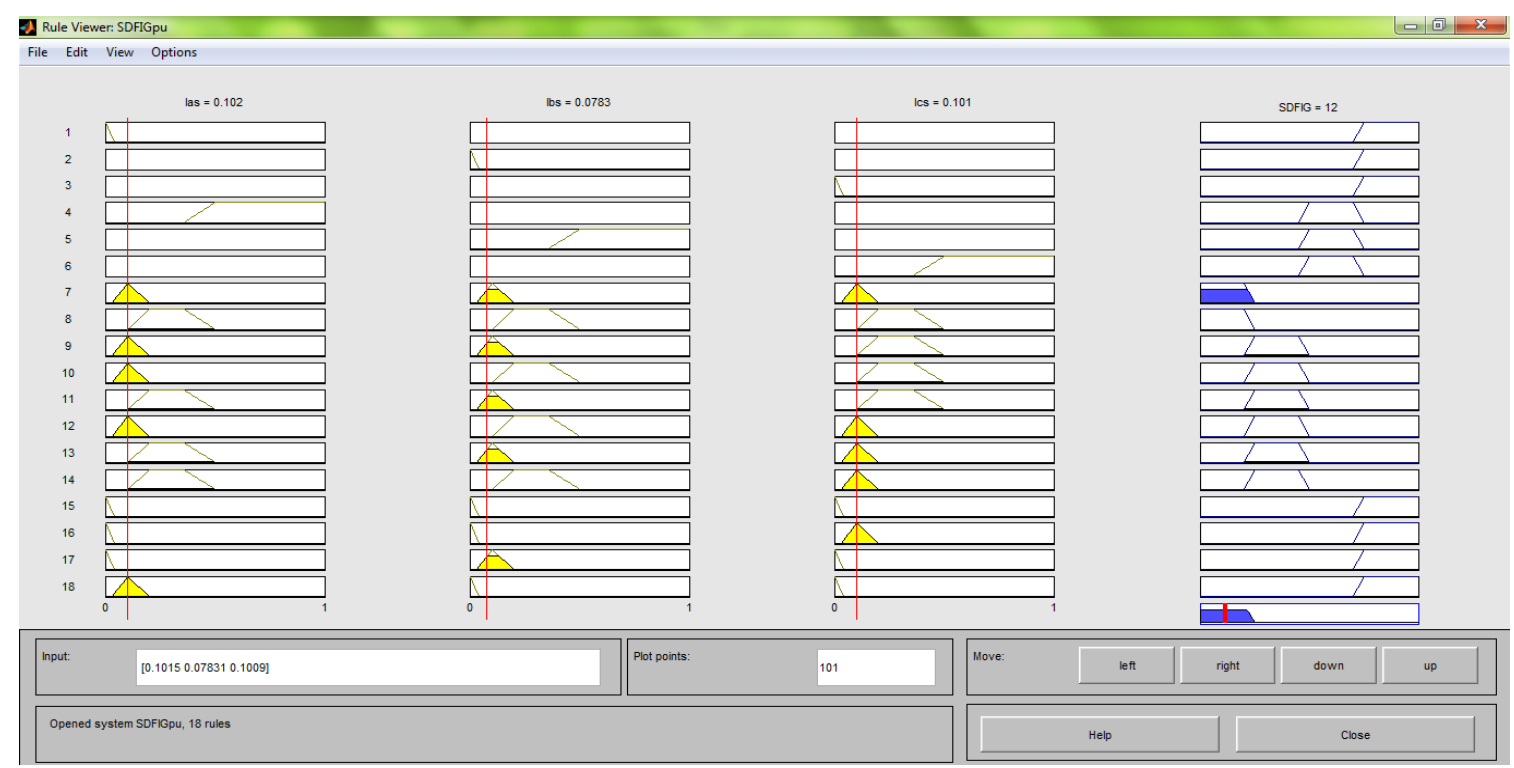

Figure 9. Rule viewer: Healthy case 


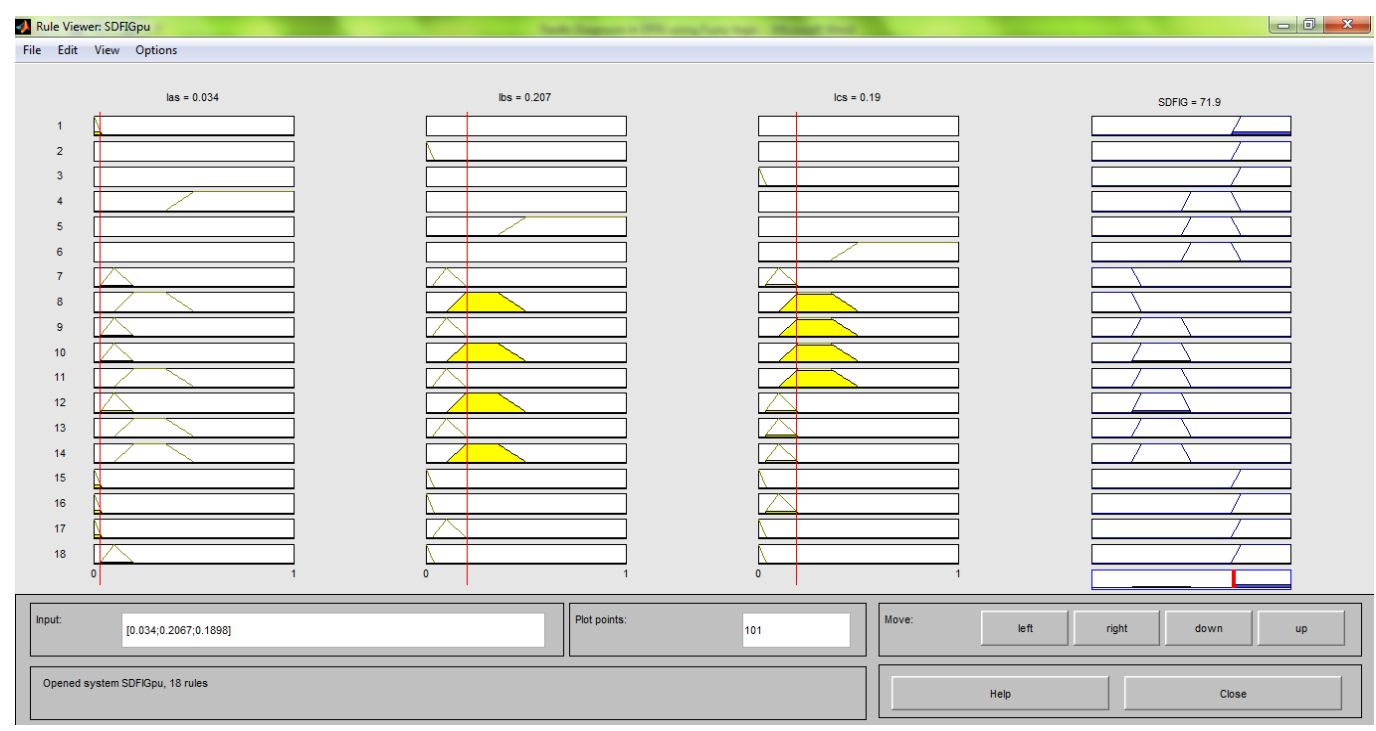

Figure 10. Rule viewer: Dangerous short circuit case

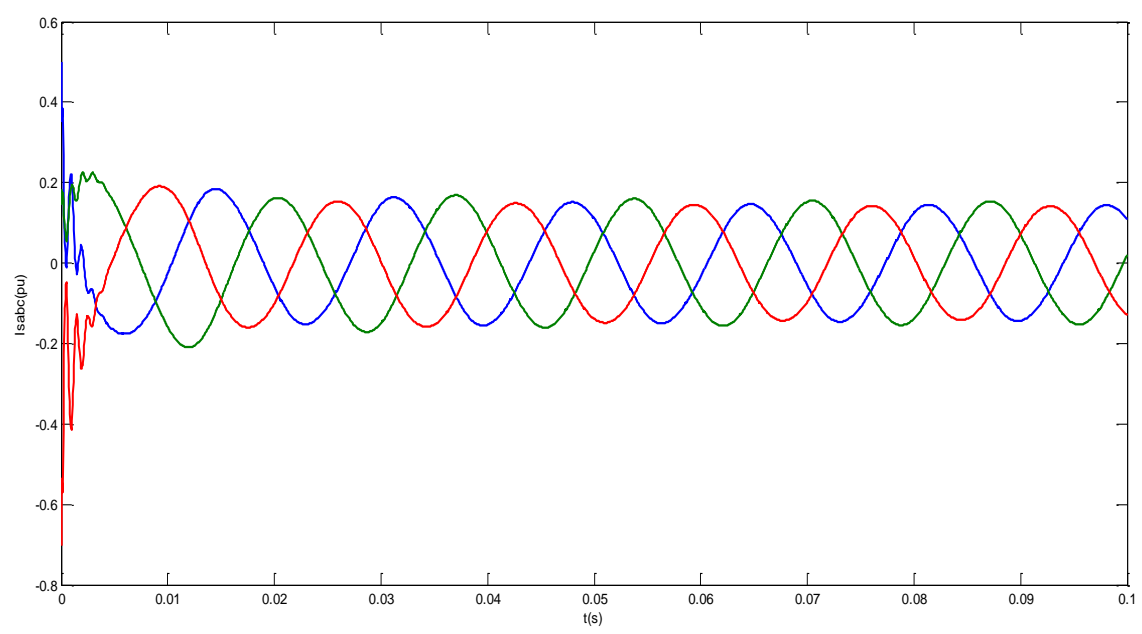

Figure 11. Stator's currents at healthy case

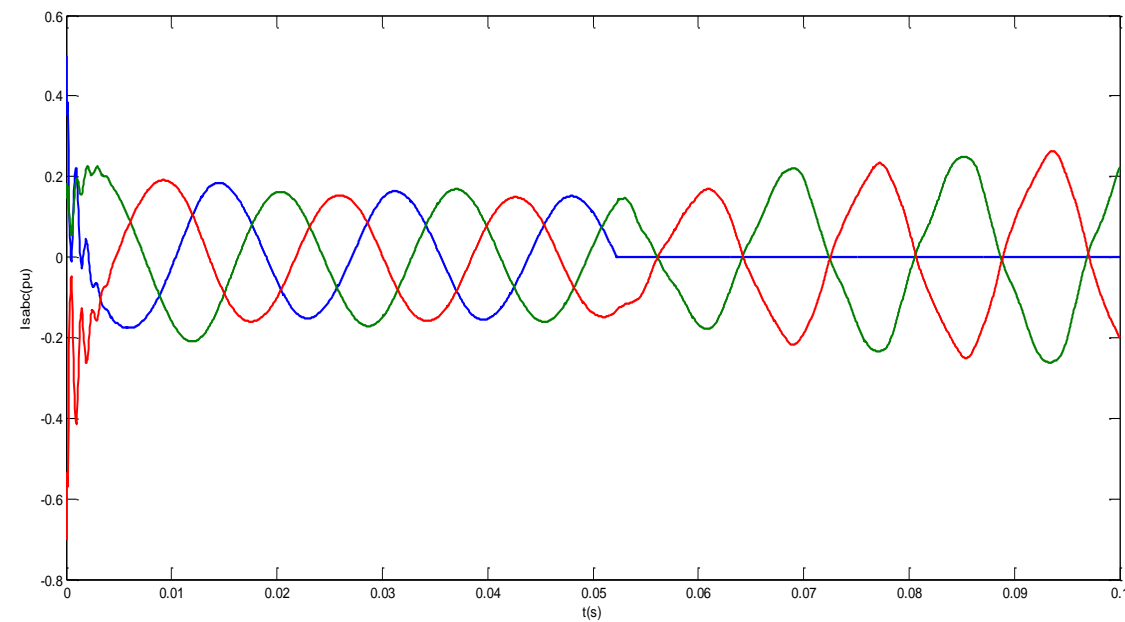

Figure 12. Stator's currents at open circuit case 


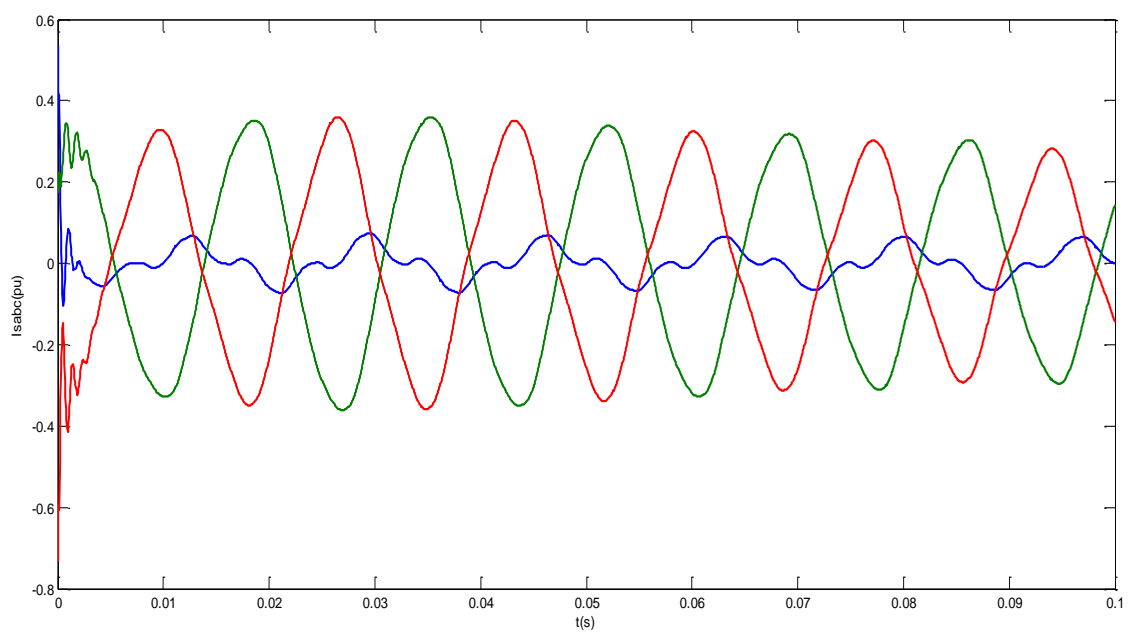

Figure 13. Stator's currents at dangerous short circuit case

\section{CONCLUSION}

The artificial intelligence is gaining many domains where the decisions are deducted from many parameters. The proposed expert system based on fuzzy logic has shown a great efficiency and a smart detect and diagnosis of the DFIG's faults using the stator currents' signatures. According to DFIG's state value, the expert system can easily identify the default's nature. As is shown at Table 1, the proposed expert system can distinguish between the gravity of the short circuit through the state DFIG's value in the cases 3 and 4.

\section{REFERENCES}

[1] National Energy Administration, 'Wind power development 13th Five-Year plan' [EB/OL]http://www.nea.gov.cn/2016-11/29/c_135867633.htm, November 29, 2016.

[2] $\mathrm{B} \mathrm{Lu}, \mathrm{Y} \mathrm{Li}, \mathrm{Z}$ Yang. "A review of recent advances in wind turbine condition monitoring and fault diagnosis[C]//Power Electronics and Machines in Wind Applications, 2009. PEMWA 2009. IEEE, 2009, pp.1-7 (2009).

[3] W Yi, F Xiaoyun, "Electric locomotive fault diagnosis expert system based on fault tree. Electric Locomotives \&Mass Transit Vehicles," 27, pp.35-36 (2004).

[4] Xiao-Wen Deng, Qing-Shui Gao, Chu Zhang, Di Hu and Tao Yang, "Rule-based Fault Diagnosis Expert System for Wind Turbine," ITM Web of Conferences 11, IST2017, pp.1-9.

[5] A. Balasubramanian, R. Muthu, "Model Based Fault Detection and Diagnosis of Doubly Fed Induction GeneratorsA Review," Energy Procedia 117 (2017), pp. 935-942.

[6] S D Koushik, T S Kishore, K Hari Krishna "Modeling and control of variable speed DFIG based wind energy conversion system,” Int. J. Egg. Sc. \& Mgmt., vol VI, Issue II, Jul-Dec 2016.

[7] Youssef Majdoub, Ahmed Abbou, Mohamed Akherraz, Rachid El Akhrif, "Design of an Improved MPPT Control of DFIG Wind Turbine under Unbalanced Grid Voltage using a Flux Sliding Mode Observer," International Journal of Power Electronics and Drive System (IJPEDS), Vol. 8, No. 4, December 2017, pp. 1723-1731.

[8] Ihedrane Yasmine, El Bekkali Chakib, Bossoufi Badre, "Power Control of DFIG-Generators for Wind Turbines Variable-Speed," International Journal of Power Electronics and Drive System (IJPEDS) Vol. 8, No. 1, March 2017, pp. 444-453.

[9] Zadeh, L.A. (1965). Fuzzy Sets. Information and Control, 8(3), pp.338-353.

[10] Medjdoub khessam, Abdeldejbar Hazzab, Bouchiba Bousmaha, M Bendjima, "Fuzzy Adaptive PI Controller for DTFC in Electric Vehicle," International Journal of Power Electronics and Drive Systems (IJPEDS), Vol 4, No 4: December 2014, pp. 557-566. 


\section{BIOGRAPHIES OF AUTHORS}
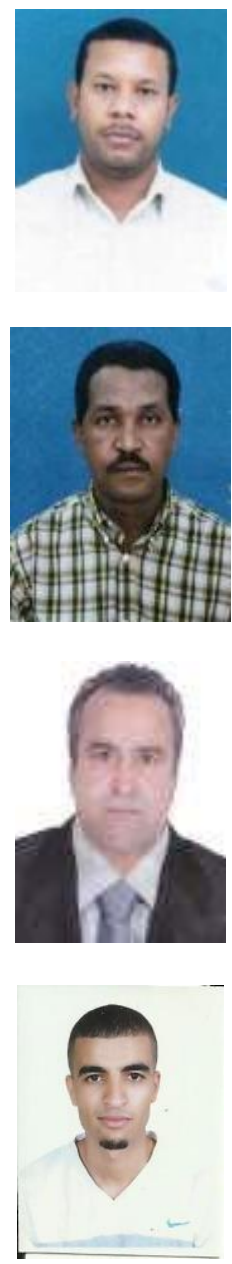

Cheriet Ahmed born on 16th february 1974 in bechar, algeriahe received the ingeniorat degree in computer science from the Oran University, Algeria in 1998 and the master degree in computer science from the Tahri Mohammed Bechar University, Algeria in 2011. In 2016, he was a laboratory membre at, Laboratory of Control Analysis and Optimization of the Electro-Energetic Systems (CAOSEE). His research interrest covers, power electronics, Control Multilevel Converters, Artificial Intelligence.

E-mail ahmed.cherietg@gmail.com

Bekri Abdelkader was born on 04th decembrey 1965 in Bechar received the state engineer degree in electrical engineering from the University of Sciences and Technology of Oran (USTO) Algeria, the M.Sc. degree from the Electrical Engineering Institute of the Tahri Mohammed Bechar University Algeria , and the Ph.D. degree from the Electrical Engineering Institute of the Tahri Mohammed Bechar University, Algeria . He is currently professor of electrical engineering at University of Bechar, Bechar, Algeria, where he is Director of the Research Laboratory of Control Analysis and Optimization of the Electro-Energetic Systems. E-mail: bekriabdkader@yahoo.fr.

Hazzab Abdeldjebar was born in 1971 in Bechar, Algeria. received the state engineer degree in electrical engineering in 1995 from the University of Sciences and Technology of Oran (USTO), Algeria the M.Sc. degree from the Electrical Engineering Institute of the USTO in 1999, and the Ph.D. degree from the Electrical Engineering Institute of the USTO in 2006. He is currently professor of electrical engineering at University of Bechar, Bechar, Algeria. His research interests include power electronics, electric drives control, and artificial intelligence and their applications

E-mail a_hazzab@yahoo.fr

Gouabi Hicham born on 20th november 1992 in bechar, algeriahe received the master degree in automation of industrial processes : automatic control from the Boumerdes University, Algeria in 2016 In 2016, he was a laboratory membre at, Laboratory of Control Analysis and

Optimization of the Electro-Energetic Systems (CAOSEE).His research interrest covers, power electronics, Control Multilevel Converters, Artificial Intelligence.

E-mail hicham.gouabi@gmail.com 